\title{
Desertification and Environmental Vulnerability. Preface
}

\author{
Dimitra Rapti-Caputo ${ }^{1}$, Massimo Iannetta ${ }^{2}$ \\ ${ }^{1}$ Department of Earth Sciences, University of Ferrara, Via Saragat 1, 44122 Ferrara, Italy \\ ${ }^{2}$ ENEA - CR Casaccia - "Sustainable Development and Innovation of Agro-industrial System" Technical Unit \\ Via Anguillarese 301, 00123 Rome, Italy
}

The term "desertification" (which is somewhat misleading) is not applied to hyper-arid zones (deserts). It is used rather to refer to a process resulting from anthropocentric and natural factors, such as land over-exploitation, overgrazing, mechanized farming, bad irrigation practices, illegal and excessive logging, bush and forest fires and deforestation due to population increase; along with these human activities, a range of climatic factors are believed to influence the process of land degradation (year-round aridity, high variability in rainfall, recurrent drought and so on). Due to these multiple causes, combatting desertification involves a wide range of measures and contributes to combatting poverty, to structural reforms and to sustainable development.

The official definition of "desertification" was formulated during the United Nations Conference on Environment and Development (Rio de Janeiro, 1992), as: "land degradation in arid, semi-arid and dry sub-humid areas resulting from various factors, including climatic variations and human activities". (Art. 1, available at http://www.unccd.int). Such definition, adopted as part of the United Nations International Convention to Combat Drought and Desertification (UNCCD) in 1994, is considered highly innovative for three main reasons:

- the term degradation is used to refer to both bio-chemical and physical characteristics of soil, and to its economic value;

- arid, semi-arid and dry sub-humid areas are the most vulnerable regions of our planet (excluding the Artic and Antartic);

- desertification is considered as resulting from the sum of natural and anthropogenic causes.

Before the Rio de Janeiro conference, desertification was not perceived as the main aspect of a worrying ecological development, but as a contingent consequence of "periods" of drought, such as the 1968-73 drought, the scarce rainfall of 1974-83, and the terrible 1984. It is only after this date that a general awareness was reached of desertification as a global phenomenon, though with local causes.

Desertification is a truly worldwide phenomenon and affects about 40 per cent of the Earth's land surface including parts of Europe. Seventy per cent of all dry areas suffer from desertification, accounting for 36 million square $\mathrm{km}$; the least developed countries are the hardest hit by desertification. Over one billion people in over 100 countries are directly affected by desertification or are at risk.

Adopting a medical terminology, we can say desertification is a complex syndrome characterized by a suite of symptoms that can vary as a function of the environmental and socio-economic context of the territory under exam. These symptoms can be related to the qualiquantitative degradation of soil and of its micro flora, of water, or of vegetation, or even to phenomena of land abandonment due to social and economic causes. These symptoms can, separately or jointly, result in the "desertification syndrome" that is generally associated with the degradation of natural resources by man, and to adverse climatic conditions.

For all these reasons desertification is a dynamic degradation process of natural resources that, being more or less gradual and slow, is often difficult to observe, identify, and recognize. Nowadays, the local risk of desertification is evaluated on the basis of indicators that can be grouped into five main categories: climate, soil, vegetation, water resources and land management. The synthetic index that is derived represents the starting point of a dynamic analysis of desertification, of the estimation of the direction and speed of change, and of the formulation of future scenarios. 